\title{
Evidence for late Pleistocene volcanism at Santa Maria Island, Azores?
}

\author{
Ricardo Ramalho (1,2,3), Rui Quartau (1,4), Alessandro Ricchi (5), José Madeira (1), and João Cruz (4)
}

(1) Instituto Dom Luiz (IDL), Faculdade de Ciências da Universidade de Lisboa, Lisbon, Portugal (raramalho@ fc.ul.pt), (2) School of Earth Sciences, University of Bristol, Bristol, United Kingdom, (3) Lamont-Doherty Earth Observatory (LDEO), Columbia University, New York, USA, (4) Divisa o de Geologia Marinha, Instituto Hidrogra' fico (IH), Lisbon, Portugal, (5) Dipartimento di Scienze Biologiche, Geologiche e Ambientali, Università di Bologna, Bologna, Italy

Santa Maria Island constitutes the oldest volcanic island edifice within the Azores Archipelago, with no onshore traces of eruptions younger than $2.8 \mathrm{Ma}$. A recent high-resolution multibeam bathymetric survey, however, revealed the presence of a seemingly young submerged tuff ring at approximately $80 \mathrm{~m}$ of water depth, on the northeastern sector of the island shelf. The outer flanks of this tuff ring are partially truncated by marine erosion, but the ring's general morphology is largely preserved, attesting to its relative young age. The ring's aspect ratio and crater size are typical of very high-energy surtseyan to taalian eruptions, implying extrusion at sea level or in very shallow waters, conditions that are incompatible with the present-day location of this volcanic feature at deeper water depths. Such characteristics therefore suggest its generation took place at approximately 13.5-13.0 ka, the last time sea level was at -80/-70 $\mathrm{m}$. An extrusion during the Last Glacial Termination - a period characterised by extremely fast sea-level rise - also helps to explain why this tuff ring was submerged without being completely razed by marine erosion. Our study therefore suggests that Santa Maria's volcanism might have extended well into the very late Pleistocene, raising important hazard implications. Future work is scheduled to confirm this hypothesis, including sampling of the volcanic products by dredging and/or by remote operated vehicle.

This publication is supported by FCT-project UID/GEO/50019/2013-IDL. 